\title{
Identification, systematic evolution and expression analyses of the AAAP gene family in Capsicum annuum
}

\author{
Xiaoxue Pan, Mingyu Hu, Zhongwei Wang, Ling Guan, Xiaoying Jiang, Wenqin Bai, Hong Wu and Kairong Lei*
}

\begin{abstract}
Background: The amino acid/auxin permease (AAAP) family represents a class of proteins that transport amino acids across cell membranes. Members of this family are widely distributed in different organisms and participate in processes such as growth and development and the stress response in plants. However, a systematic comprehensive analysis of AAAP genes of the pepper (Capsicum annuum) genome has not been reported.

Results: In this study, we performed systematic bioinformatics analyses to identify AAAP family genes in the $C$. annuum 'Zunla-1' genome to determine gene number, distribution, structure, duplications and expression patterns in different tissues and stress. A total of 53 CaAAAP genes were identified in the 'Zunla-1' pepper genome and could be divided into eight subgroups. Significant differences in gene structure and protein conserved domains were observed among the subgroups. In addition to CaGAT1, CaATL4, and CaVAAT1, the remaining CaAAAP genes were unevenly distributed on 11 of 12 chromosomes. In total, 33.96\% (18/53) of the CaAAAP genes were a result of duplication events, including three pairs of genes due to segmental duplication and 12 tandem duplication events. Analyses of evolutionary patterns showed that segmental duplication of AAAPs in pepper occurred before tandem duplication. The expression profiling of the CaAAAP by transcriptomic data analysis showed distinct expression patterns in various tissues and response to different stress treatment, which further suggest that the function of CaAAAP genes has been differentiated.
\end{abstract}

Conclusions: This study of CAAAAP genes provides a theoretical basis for exploring the roles of AAAP family members in C. annuum.

Keywords: Capsicum annuum, Amino acid/auxin permease, Systematic evolution, Gene expression analyses

\section{Background}

Plants obtain nitrogen by absorbing ammonia, nitrate, amino acids, and soluble peptides from the soil. Nitrogen absorption and transport is mediated by several types of transport proteins, including ammonium transport proteins (AMTs), nitrate transport proteins (NRTs), amino acid transport proteins (AATs) and peptide transport proteins (PTRs) [1]. In plants, AATs are transmembrane (TM)

\footnotetext{
*Correspondence: leikairong@126.com

Biotechnology Research Center, Chongqing Academy of Agricultural Sciences/Chongqing Key Laboratory of Adversity Agriculture Research, Chongqing 401329, China
}

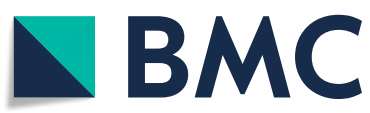

proteins that transport amino acids from the extracellular environment to the intracellular environment [2]. According to conserved sequence and structure motifs, the plant AAT superfamily consists of the amino acid/auxin permease (AAAP) and amino acid-polyamine-choline (APC) gene families [3]. The AAAP subfamily includes eight subclasses of transporters: amino acid permeases (AAPs), lysinehistidine transporters (LHTs), proline transporters (ProTs), $\gamma$-aminobutyric acid transporters (GATs), putative auxin transporters (AUXs), similar to ANT1-like aromatic and neutral amino acid transporters (ANTs), and amino acid transporter-like (ATLa and ATLb) subfamilies $[4,5]$. AAAP

(c) The Author(s). 2021 Open Access This article is licensed under a Creative Commons Attribution 4.0 International License, which permits use, sharing, adaptation, distribution and reproduction in any medium or format, as long as you give appropriate credit to the original author(s) and the source, provide a link to the Creative Commons licence, and indicate if changes were made. The images or other third party material in this article are included in the article's Creative Commons licence, unless indicated otherwise in a credit line to the material. If material is not included in the article's Creative Commons licence and your intended use is not permitted by statutory regulation or exceeds the permitted use, you will need to obtain permission directly from the copyright holder. To view a copy of this licence, visit http://creativecommons.org/licenses/by/4.0/ The Creative Commons Public Domain Dedication waiver (http://creativecommons.org/publicdomain/zero/1.0/) applies to the data made available in this article, unless otherwise stated in a credit line to the data. 
genes are widely present in plants, including Arabidopsis (46 genes) [6], rice (58 genes) [7], maize (71 genes) [8], poplar (71 genes) [9], potato (52 genes) [10], moso bamboo(55 genes) [11] and Medicago truncatula(86 genes) [12].

The first amino acid transporter protein (AtAAP1/ NAT2) isolated from plants belongs to the AAP family. There are eight members in Arabidopsis, and AtAAP transports neutral, acidic and cationic amino acids with different specificities and affinities [13, 14]. AtAAP1 is highly expressed in Arabidopsis cotyledons and the endosperm, and mediates uptake of amino acids to developing embryo or root cells [15-17]. AtAAP2 is localized to the plasma membrane and the phloem, and the aap2 mutant exhibits altered xylem-phloem transfer of amino acids, which affects metabolism and results in increased seed yield and oil content in Arabidopsis [18]. AtAAP3 is exclusively expressed in roots and AtAAP4 is primarily expressed in source leaves, stems, and flowers, AtAAP5 has been observed in all tissues [19]. In the aap6 mutant, the amino acid content of the Arabidopsis sieve elements was reduced but not affect leaves aphid herbivores [20]. AtAAP8 participates in the early seed development in Arabidopsis [21]. OsAAP3 and OsAAP5 regulate tiller number and grain yield in rice [22, 23], and overexpression of OsAAP6 increases grain protein content and improves rice nutritional quality [24]. In addition, there are reports of AAP subfamily members in other species, including StAAP1 [25], PvAAP1 [26], PtAAP11 [27], VfAAP1 and VfAAP3 [28].

AtLHT1 localizes on the surface of roots in young seedlings and in pollen and mediates uptake of amino acids from the root to the mesophyll cells through the xylem $[29,30]$. Under conditions of nitrogen deficiency in particular, overexpression of AtLHT1 can increase the efficiency of nitrogen utilization [30]. AtLHT2 localizes to the tapetum of Arabidopsis anthers [31]. AtLHT6 is expressed in buds, flowers, and roots; AtLHT4 expression is increased in developed buds compared to mature flowers; and expression of AtLHT5 peaks in flowers [32, 33]. OsLHT6 is specifically expressed in new shoot meristems [7], and PgLHT plays an important role in the growth and development of the ginseng root system [34]. The GAT subfamily mainly transports $\gamma$ aminobutyric acid (GABA) and GABA-related compounds; the highest expression of AtGAT1 is observed in flowers and under conditions of elevated GABA [35]. AtANT1 is expressed in all organs, with the highest abundance in flowers and cauline leaves, and mediates transport of aromatic and neutral amino acids, arginine, indole-3-acetic acid, and 2, 4-dichlorophenoxyacetic acid [36]. AtAUX1 is a high-affinity transporter of indoleacetic acid (IAA), and AtAUX1 and AtLAX3(a homolog of AtAUX1) are mainly expressed in roots and promote lateral root formation $[37,38]$. The expression of OsAUX subfamily members is also tissue-specific: OsAUX4 is preferentially expressed in new shoot meristems, and OsAUX2 and OsAUX5 are specifically expressed in young roots, which suggests a role in the formation and development of root systems [7]. MtLAX2, a functional homolog of AtAUX1, is required for nodule organogenesis [39]. The ProTs subfamily is responsible for transporting proline, glycinebetaine (GB) and GABA. AtProT1 is expressed in the phloem or phloem parenchyma cells, which indicates a role in the long-distance transport of proline [40]. By contrast, AtProT2 is only expressed in root epidermis and cortical cells; AtProT3 is more highly in leaf epidermal cells [40]. HvProT2 is constitutively expressed in both leaves and roots, and heterologous expression experiments have shown that the affinity of $H v P r o T 2$ is highest for glycinebetaine [41]. AtAVT3 and AtAVT4 encode amino acid efflux proteins located in the vacuolar membrane, where they mediate transport of alanine and proline [42].

Pepper is an annual or perennial plant that belongs to the Solanaceae family; it is an important vegetable crop in China, which is number one in the world in terms of planting area and output (http://www.fao.org/faostat/en/ ). The pepper Zunla-1 (C. annuum L.) genome contains 34,476 protein-coding loci on 12 different chromosomes. Although the roles of many AAAPs in plants have been well characterized, members of the AAAP gene family in pepper have not been studied. We used bioinformatics to identify the AAAP gene family members in pepper and systematically analyzed the chromosome distribution, gene structure, evolution characteristics, and expression patterns of $A A A P$ genes to provide a theoretical basis for exploring the roles of AAAPs in pepper.

\section{Results}

\section{Identification of AAAP genes in pepper}

To explore the AAAP protein family in pepper, we used one domain (PF01490) searche of Pepper Genome Database2 (http://peppersequence.genomics.cn/page/); the HMM profile was used as a query and each putative AAAP protein sequences was verified by SMART, CDD and Pfam analyses. A total of 53 AAAP genes were identified and renamed in pepper according to their affinities within gene subfamilies; CaGAT1, CaANL4 and CaVAAT1, were not anchored to chromosomes (Table 1). Gene lengths ranged from 669 (CaLHT4) to $2532 \mathrm{bp}$ (CaAAP4), the molecular weight varies from $24.43 \mathrm{kDa}$ (CaLHT4) to $93.22 \mathrm{kDa}$ (CaAAP4). The isoelectric points (pIs) of CaAAAP proteins ranged from 4.27 (CaVAAT5) to $10.06(\mathrm{CaANT} 5)$; the majority of proteins (83\%) had pIs more than 7.0, which indicates that AAAP proteins in pepper may represent a class of basic protein.

We studied the exon/intron arrangement of the coding sequences of $C a A A A P$ genes in their genome sequences and found that $13.21 \%(7 / 53)$ of pepper $A A A P$ genes 
Table 1 The general information and sequence characterization of 53 CaAAAP genes

\begin{tabular}{|c|c|c|c|c|c|c|c|c|c|}
\hline \multirow[t]{2}{*}{ S.N. } & \multirow[t]{2}{*}{ Gene $^{a}$} & \multirow[t]{2}{*}{ Locus $^{b}$} & \multirow[t]{2}{*}{ Location $^{c}$} & \multirow[t]{2}{*}{ ORF(bp) ${ }^{d}$} & \multirow[t]{2}{*}{ Exon $^{e}$} & \multicolumn{3}{|l|}{ Protein $^{f}$} & \multirow{2}{*}{$\begin{array}{l}\text { TM } \\
\text { region }\end{array}$} \\
\hline & & & & & & Size (aa) & $M W(d)$ & pl & \\
\hline & AAP grou & & & & & & & & \\
\hline 1 & CAAAP1 & Capana07g002429 & Chr07:220179435-220,181,692 & 1335 & 7 & 444 & $49,460.8$ & 8.72 & 11 \\
\hline 2 & CAAAP2 & Capana07g002430 & Chr07:220188828-220,192,330 & 1869 & 10 & 622 & $68,584.1$ & 8.46 & 14 \\
\hline 3 & CAAAP3 & Capana07g002431 & Chr07:220195003-220,198,004 & 1410 & 7 & 469 & $51,763.2$ & 8.45 & 10 \\
\hline 4 & CAAAP4 & Capana07g002432 & Chr07:220225817:220233681 & 2532 & 13 & 843 & $93,224.4$ & 8.88 & 17 \\
\hline 5 & CAAAP5 & Capana04g000780 & Chr04:14469803:14475148 & 1446 & 7 & 481 & $52,757.7$ & 8.81 & 10 \\
\hline 6 & CAAAP6 & Capana12g000826 & Chr12:27187513:27194231 & 1467 & 7 & 488 & $53,825.3$ & 8.94 & 9 \\
\hline 7 & CAAAP7 & Capana08g002210 & Chr08:143014796:143019992 & 1419 & 7 & 472 & $51,747.8$ & 9.12 & 11 \\
\hline 8 & CAAAP8 & Capana04g001588 & Chr04:67204663:67207202 & 1434 & 6 & 477 & $52,413.8$ & 8.27 & 10 \\
\hline 9 & CAAAPS & Capana06g001752 & Chr06:50038242:50040303 & 1419 & 6 & 472 & $51,681.9$ & 7.84 & 10 \\
\hline \multirow[t]{2}{*}{10} & CaAAP10 & Capana05g001770 & Chr05:174328892:174330262 & 1020 & 3 & 339 & $37,207.9$ & 6.86 & 7 \\
\hline & LHT grour & & & & & & & & \\
\hline 11 & CaLHT1 & Capana02g003614 & Chr02:162887482:162890584 & 1350 & 8 & 449 & 50,428 & 8.6 & 9 \\
\hline 12 & CaLHT2 & Capana02g003615 & Chr02:162905774:162912940 & 1266 & 7 & 421 & 47,443 & 8.24 & 9 \\
\hline 13 & CaLHT3 & Capana02g003616 & Chr02:162914284:162921151 & 1332 & 8 & 443 & $49,858.6$ & 9.08 & 11 \\
\hline 14 & CaLHT4 & Capana04g002888 & Chr04:215599914:215604069 & 1227 & 9 & 408 & $46,113.8$ & 8.27 & 7 \\
\hline 15 & CaLHTS & Capana04g001881 & Chr04:130533897:130536648 & 1329 & 6 & 442 & $49,917.6$ & 8.06 & 10 \\
\hline 16 & CaLHT6 & Capana11g000230 & Chr11:5761051:5762379 & 1329 & 1 & 442 & $49,944.5$ & 9.1 & 10 \\
\hline 17 & CaLHTT & Capana03g001379 & Chr03:25005836:25008812 & 1329 & 7 & 442 & $49,012.6$ & 9.4 & 11 \\
\hline 18 & CaLHT8 & Capana05g000336 & Chr05:7406911:7414486 & 1065 & 7 & 354 & $39,858.5$ & 9.42 & 7 \\
\hline 19 & CaLHT9 & Capana11g002248 & Chr11:216341951:216346445 & 1311 & 8 & 436 & $48,573.9$ & 9.03 & 8 \\
\hline 20 & CaLHT1O & Capana04g000478 & Chr04:7738487:7744000 & 1581 & 5 & 526 & $57,977.4$ & 9.61 & 9 \\
\hline 21 & CaLHT11 & Capana04g000098 & Chr04:1109665:1112218 & 1338 & 5 & 445 & $49,110.6$ & 8.68 & 10 \\
\hline 22 & CaLHT12 & Capana08g002793 & Chr08:152269921:152272976 & 1713 & 5 & 570 & 61,963 & 9.55 & 9 \\
\hline 23 & CaLHT13 & Capana11g000398 & Chr11:11019799:11021033 & 708 & & 235 & $25,865.9$ & 9.01 & 2 \\
\hline \multirow[t]{2}{*}{24} & CaLHT14 & Capana04g000106 & Chr04:1178475:1183677 & 669 & & 222 & $24,427.3$ & 8.47 & 3 \\
\hline & GAT group & & & & & & & & \\
\hline 25 & CaGAT1 & Capana00g003418 & Chr00:545297054:545303475 & 1365 & 7 & 454 & $49,950.5$ & 8.68 & 10 \\
\hline \multirow[t]{2}{*}{26} & CaGAT2 & Capana11g000210 & Chr11:5435275:5440152 & 1092 & 6 & 363 & $39,923.8$ & 9.98 & 9 \\
\hline & ProT grou & & & & & & & & \\
\hline 27 & CaProT1 & Capana05g001989 & Chr05:191409867:191415970 & 1320 & 7 & 439 & $47,836.8$ & 9.73 & 12 \\
\hline 28 & CaProT2 & Capana05g001990 & Chr05:191424542:191430181 & 1347 & 7 & 448 & $49,162.1$ & 9.4 & 11 \\
\hline \multirow[t]{2}{*}{29} & CaProT3 & Capana03g002827 & Chr03:118029421:118036334 & 1344 & 7 & 447 & $49,190.2$ & 9.61 & 12 \\
\hline & AUX grou & & & & & & & & \\
\hline 30 & CaAUXI & Capana09g001555 & Chr09:181029189:181033262 & 1467 & 7 & 488 & $54,841.3$ & 8.15 & 10 \\
\hline 31 & CaAUX2 & Capana10g001370 & Chr10:147549183:147556929 & 1467 & 7 & 488 & $54,912.8$ & 8.56 & 10 \\
\hline 32 & CaAUX3 & Capana04g001744 & Chr04:99262090:99266939 & 1317 & 8 & 438 & $49,663.3$ & 8.25 & 9 \\
\hline \multirow[t]{2}{*}{33} & CaAUX4 & Capana08g002704 & Chr08:150979738:150984984 & 1482 & 8 & 493 & $55,541.5$ & 8.75 & 10 \\
\hline & ANT grou & & & & & & & & \\
\hline 34 & CAANT1 & Capana02g002432 & Chr02:144978448:144979728 & 1281 & 1 & 426 & $46,665.9$ & 7.92 & 11 \\
\hline 35 & CAANT2 & Capana02g002433 & Chr02:144981268:144982602 & 1335 & 1 & 444 & $48,548.7$ & 4.74 & 11 \\
\hline 36 & CAANT3 & Capana02g002434 & Chr02:144983909:144985192 & 1284 & 1 & 427 & $46,457.5$ & 4.82 & 11 \\
\hline 37 & CAANT4 & Capana04g002414 & Chr04:201839016:201840293 & 1278 & 1 & 425 & $46,811.9$ & 7.45 & 11 \\
\hline
\end{tabular}


Table 1 The general information and sequence characterization of 53 CaAAAP genes (Continued)

\begin{tabular}{|c|c|c|c|c|c|c|c|c|c|}
\hline \multirow[t]{2}{*}{ S.N. } & \multirow[t]{2}{*}{ Gene $^{a}$} & \multirow[t]{2}{*}{ Locus $^{b}$} & \multirow[t]{2}{*}{ Location $^{c}$} & \multirow[t]{2}{*}{ ORF(bp) $)^{d}$} & \multirow[t]{2}{*}{ Exon ${ }^{\mathrm{e}}$} & \multicolumn{3}{|l|}{ Protein $^{f}$} & \multirow{2}{*}{$\begin{array}{l}\text { TM } \\
\text { region }^{g}\end{array}$} \\
\hline & & & & & & Size (aa) & $M W(d)$ & $\mathrm{pl}$ & \\
\hline \multirow[t]{2}{*}{38} & CAANT5 & Capana03g004210 & Chr03:248829547:248830964 & 930 & 2 & 309 & $33,786.3$ & 10.06 & 10 \\
\hline & ATLa gro & & & & & & & & \\
\hline 39 & CAATL1 & Capana06g001998 & Chr06:75940086:75942122 & 846 & 3 & 281 & $30,550.9$ & 4.94 & 3 \\
\hline 40 & CAATL2 & Capana03g000522 & Chr03:7178172:7179590 & 1419 & 1 & 472 & $51,153.5$ & 5.43 & 10 \\
\hline 41 & CAATL3 & Capana05g002081 & Chr05:197860240:197862960 & 1302 & 6 & 433 & $47,459.1$ & 8.35 & 11 \\
\hline 42 & CAATL4 & Capana00g004937 & Chro0:676629079:676631743 & 1320 & 5 & 439 & $47,898.6$ & 8.55 & 11 \\
\hline 43 & CAATL5 & Capana04g000715 & Chr04:12477359:12484737 & 1344 & 5 & 447 & $48,657.5$ & 8.36 & 11 \\
\hline 44 & CAATL6 & Capana02g000804 & Chr02:93929776:93933801 & 1407 & 5 & 468 & $50,795.2$ & 8.78 & 11 \\
\hline \multirow[t]{2}{*}{45} & CAATL7 & Capana02g003206 & Chr02:157224580:157228911 & 1383 & 5 & 460 & $49,954.5$ & 8.55 & 11 \\
\hline & ATLb gro & & & & & & & & \\
\hline 46 & CAVAAT1 & Capana00g004212 & Chr00:618994856:618996151 & 1296 & 1 & 431 & $46,618.7$ & 7.96 & 8 \\
\hline 47 & CAVAAT2 & Capana04g001726 & Chr04:93008498:93010474 & 1281 & 3 & 426 & $46,958.9$ & 7.71 & 10 \\
\hline 48 & CAVAAT3 & Capana12g002556 & Chr12:222093246:222094767 & 1017 & 2 & 338 & 36,992 & 7.91 & 9 \\
\hline 49 & CaVAAT4 & Capana05g002349 & Chr05:207916251:207920239 & 1140 & 3 & 379 & $41,865.5$ & 9.04 & 9 \\
\hline 50 & CAVAAT5 & Capana03g003057 & Chr03:162840327:162847744 & 1395 & 9 & 464 & $51,484.7$ & 4.27 & 7 \\
\hline 51 & CaVAAT6 & Capana10g001696 & Chr10:173666186:173669984 & 1608 & 11 & 535 & $57,908.7$ & 5.19 & 10 \\
\hline 52 & CAVAAT7 & Capana03g002859 & Chr03:127734852:127743213 & 1338 & 7 & 445 & $48,690.8$ & 4.98 & 5 \\
\hline 53 & CaVAAT8 & Capana12g002523 & Chr12:220748120:220761121 & 1989 & 15 & 662 & $73,214.4$ & 5.85 & 8 \\
\hline
\end{tabular}

S.N serial number, ORF open reading frame, $b p$ base pair, aa amino acids, $M W$ molecular weight, $p /$ isoelectric point, $T M$ transmembrane, $N A$ not available

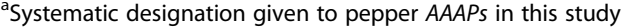

${ }^{b}$ Locus identity number of AAAP assigned by Pepper Genome Database2 (http://peppersequence.genomics.cn/page/)

'Chromosomal localization of pepper AAAP genes

${ }^{\mathrm{d}}$ Length of the open reading frame

eNumber of extrons obtained from GSDS by comparing sequences between transcript and genome (Gene Structure Display Server; http://gsds.cbi.pku.edu.cn/)

fProtein characterization of CaAAAPs obtained from EXPASY server (http://web.expasy.org/protparam/)

${ }^{9}$ Number of transmembrane segments possessed by CaAAAPs, predicted by the TMHMM Server v2.0

contained a single exon, 3.77\% (2/53) had a single intron, and $83.02 \%$ had 1 to 14 introns (Fig. 1). Prediction of TM regions showed that most CaAAAPs (77.36\%) had 8-11. Similar numbers of TMs regions were found in several subfamilies (e.g., $10 \mathrm{TMs}$ in the AUX subfamily and 11 TMs in the ANT and ATLa subfamilies; Table 1 and Additional file 1:Figure S1). Thus, members of the same subfamily have a conserved structure.

Conserved domains of pepper AAAP proteins were analyzed with the MEME server and a total of 20 conserved motifs were identified (Fig. 1, Additional file 3: Table S1). Motifs 1 (44/53), 2 (42/53), and 7 (49/53) were widespread among members of the CaAAAP family. Some subfamilies included several specific motifs. For example, the LHT and GAT subfamilies contained motifs $3,12,13$, and 14, whereas motif 5 was only found in the LHT, AAP, GAT, and ProT subfamilies. Motifs 9, 10 , and 17 were only present in the AUX subfamily; motifs 15 and 18 were only present in the ANT subfamily; motifs 16 and 19 were only present in the ATLa subfamily. Similar numbers of motifs were found in the ProT and AUX subfamilies (Fig. 1), which suggests that the structures of these subfamilies are highly conserved.

\section{Phylogenetic and structural analyses of AAAP proteins in pepper}

To further understand the homology between the AAAP gene families of pepper and other plant species (Table 2), we constructed an unrooted phylogenetic tree of fulllength AAAPs from pepper, potato, rice and Arabidopsis was constructed (Fig. 2). We found that the genes CaAAAP, StAAAP, OsAAAP and AtAAAP were divided into eight distinct subfamilies, which indicates that the AAAP gene family has eight subfamilies in angiosperms. In pepper, the LHT subfamily was the largest (26.42\%; 14 genes), whereas the GAT subfamily comprised only two genes. and the numbers of genes in the subgroups GAT, ProT,AUX and ANT were the same as or similar to those in potato, rice, and Arabidopsis.

\section{Chromosomal location and duplication analyses}

We used Mapchart 2.30 mapping to identify the chromosomal location of AAAP genes in the pepper genome (Fig. 3). In addition to CaGAT1, CaANL4 and CaVATT1, the remaining 50 genes were unevenly distributed on 11 of 12 chromosomes; no genes were mapped to chromosomes 1 (Fig. 3, Table 1). Most of the 


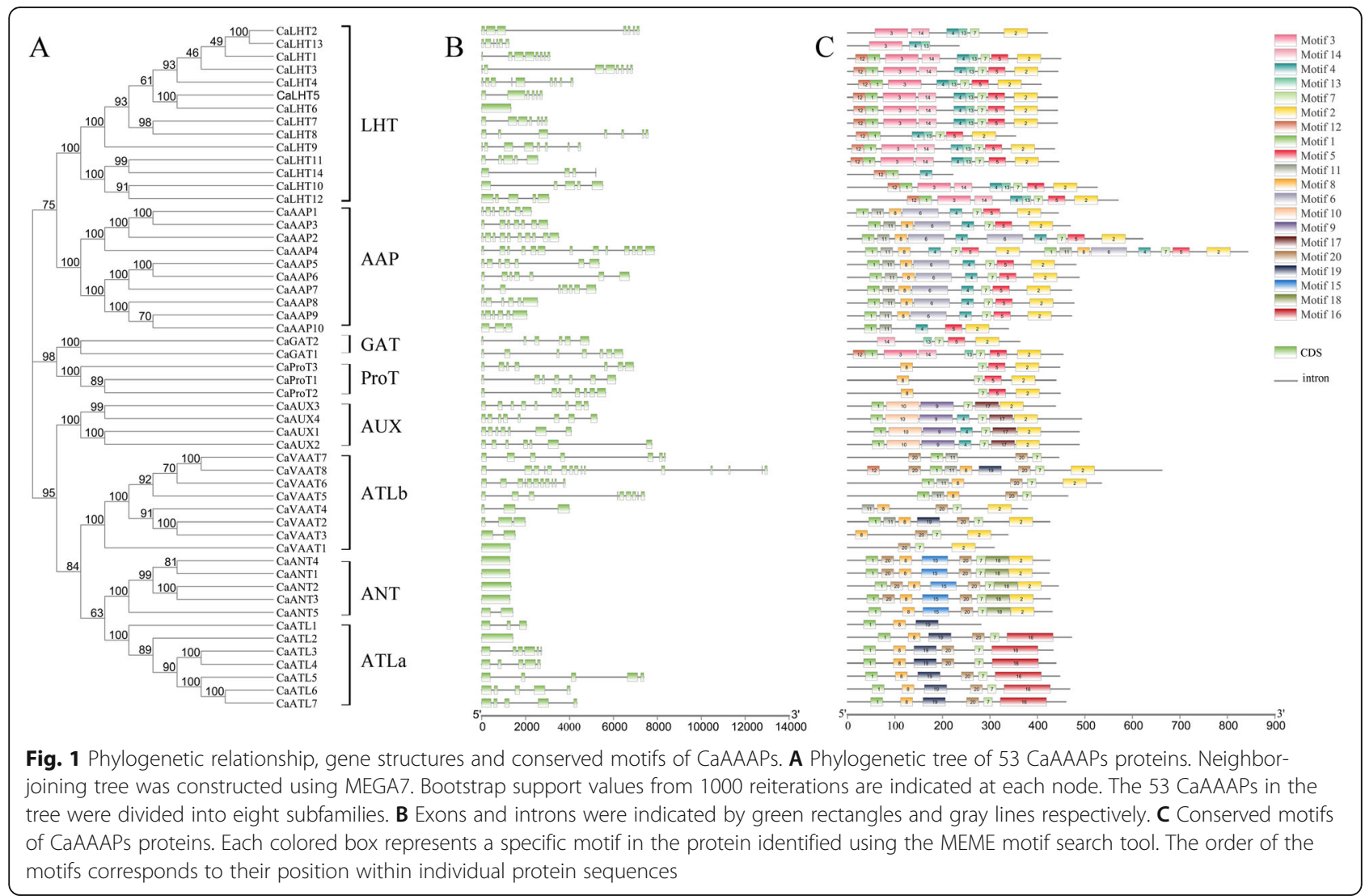

genes were mapped to the bottom of chromosomes 2, 5, 7 and 8 , whereas the genes on chromosome 11 were mostly mapped to the top. A total of $58.5 \%$ (31/53) of genes were mapped to chromosome 2, 3, 4 and 5, which contained 8 , 6, 11 and 6 genes, respectively. Only one gene was located on chromosome 9, and two to four genes were mapped to the remaining chromosomes (Fig. 3).

To identify the duplication events of $A A A P$ genes in pepper, we analyzed the 53 full-length AAAP protein sequences using MCScanX. According to the defined criterion of separation five or fewer genes with more than $50 \%$ similarity at protein level, $33.96 \%$ (18 of 53 ) originated from the duplication events (Fig. 3). Twelve genes $(22.64 \%)$ were arranged in tandem duplication and organized into four groups. Two pairs of tandem duplicate genes were identified on chromosome 2; chromosomes 5 and 7 each contained one pair (Fig. 3). Three segmental duplication blocks were located on chromosomes 2, 4 and 12, representing $11.32 \%$ of all CaAAAP genes (6/53) (Fig. 3, Additional file 2: Figure S2). Furthermore, high-sequence similarity occurred in duplicated genes: CaAAP1 and $C a A A P 3$, which originated via tandem duplication, were

Table 2 Comparative analysis of Amino acid/auxin permease (AAAP) proteins between Capsicum and other plant species

\begin{tabular}{|c|c|c|c|c|c|c|c|c|c|c|c|c|}
\hline \multirow[t]{2}{*}{ Specie } & \multicolumn{8}{|c|}{ AAAP subfamily } & \multirow{2}{*}{$\begin{array}{l}\text { \# of } \\
\text { AAAPproteins }\end{array}$} & \multirow{2}{*}{$\begin{array}{l}\text { \# of } \\
\text { Proteins }\end{array}$} & \multirow{2}{*}{$\begin{array}{l}\text { \# \% of } \\
\text { AAAPproteins }\end{array}$} & \multirow[t]{2}{*}{ Reference } \\
\hline & AAP & LHT & GAT & ProT & AUX & ANT & ATLa & $A T L b$ & & & & \\
\hline A. thaliana & 8 & 10 & 2 & 3 & 4 & 4 & 5 & 10 & 46 & 25,498 & 0.18 & {$[6]$} \\
\hline P.edulis & 16 & 8 & 6 & 3 & 7 & 2 & 6 & 7 & 55 & 31,987 & 0.17 & [11] \\
\hline O. sativa & 19 & 6 & 4 & 3 & 5 & 4 & 7 & 10 & 58 & 35,825 & 0.16 & {$[7]$} \\
\hline Z. mays & 15 & 24 & 2 & 2 & 5 & 3 & 6 & 14 & 71 & 39,591 & 0.18 & {$[8]$} \\
\hline M.truncatula & 26 & 18 & 4 & 3 & 5 & 3 & 13 & 14 & 86 & 44,623 & 0.19 & {$[12]$} \\
\hline P. trichocarpa & 17 & 13 & 7 & 3 & 8 & 4 & 8 & 11 & 71 & 45,000 & 0.16 & [9] \\
\hline S.tuberosum & 8 & 11 & 3 & 4 & 5 & 5 & 8 & 8 & 52 & 39,031 & 0.13 & [10] \\
\hline C.annuum & 10 & 14 & 2 & 3 & 4 & 5 & 7 & 8 & 53 & 34,476 & 0.15 & \\
\hline
\end{tabular}

$A A P$ amino acid permease, $L H T$ lysine and histidine transporter, GAT g -aminobutyric acid transporter, ProT proline transporter, AUX auxin transporter, ANT aromatic and neutral amino acid transporter, ATL amino acid transporter-like 


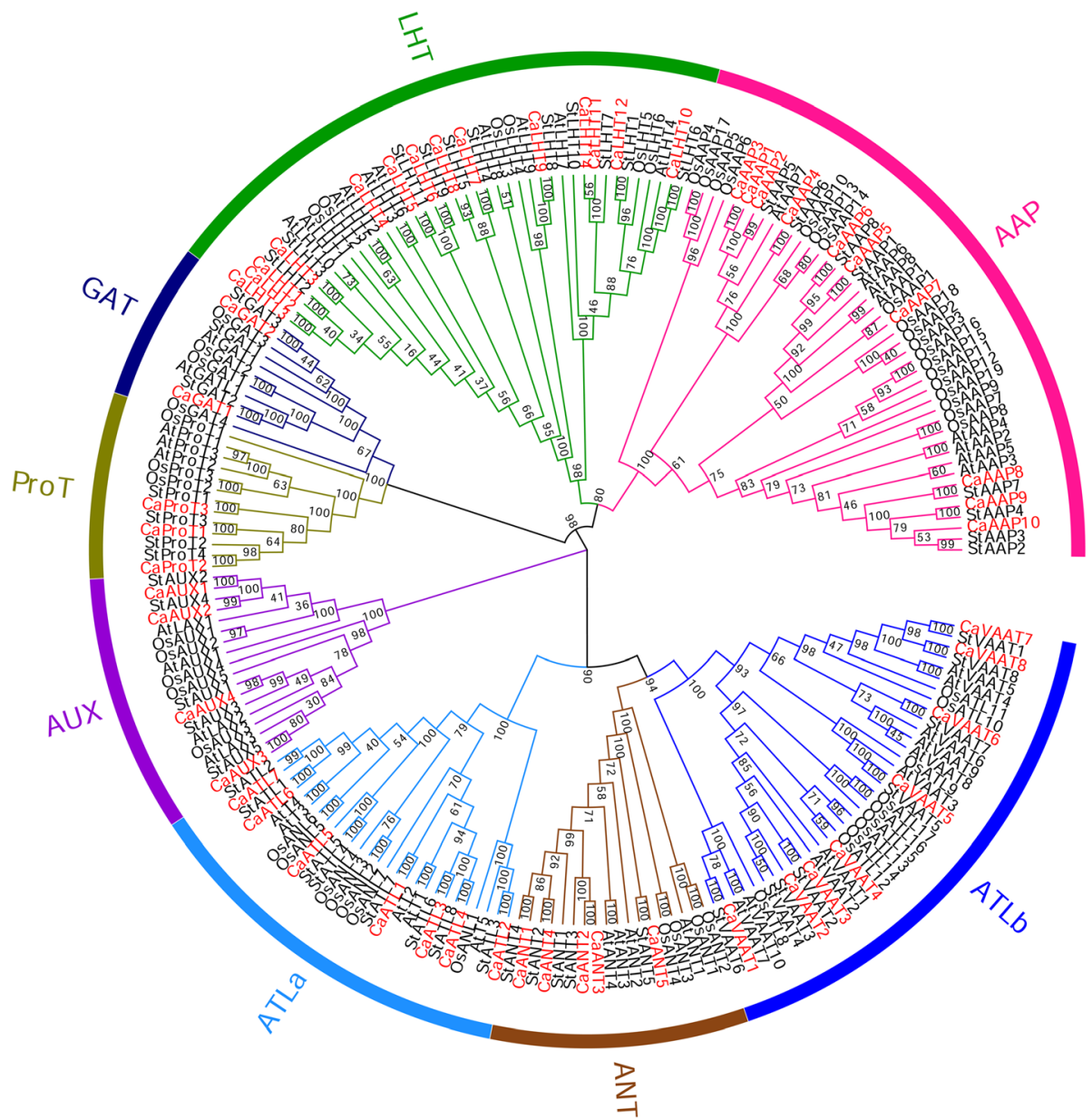

Fig. 2 Phylogenetic relationships of pepper, potato, rice, and Arabidopsis AAAP proteins. Multiple sequence alignment of full-length proteins was performed by Clustal X1.83 and the phylogenetic tree was constructed using MEGA7 with the neighbor-joining method. The tree was divided into eight subgroups, marked by different color backgrounds

94.28\% similar, whereas CaANT1 and CaANT4, which were a result of segmental duplication, exhibited $81.79 \%$ similarity.

Based on chromosomal distribution and phylogenetic and sequence similarity analyses, we identified seven pairs of paralogs in the pepper AAAP family (Table 3). Two pairs of paralogs (CaANT1 and CaANT4, and CaAAP5 and CaAAP6) participated in segmental duplications on different chromosomes. Five pairs (CaANT1 and CaANT2, CaANT2 and CaANT3, CaANT1 and

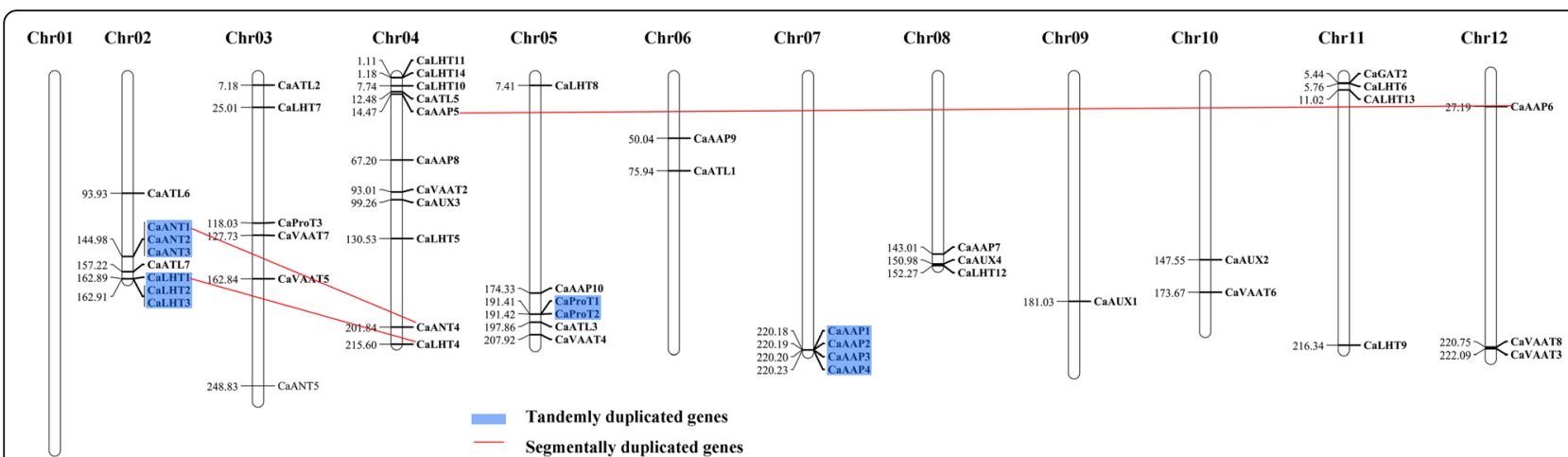

Fig. 3 Chromosomal localization and gene duplication events of CAAAAP genes. Respective chromosome numbers are indicated at the top of each bar. Tandem duplicated genes are marked on a blue background. Segmental duplicated genes are shown by red line 
Table 3 Ka-Ks calculation for each pair of AAAP paralogs in pepper

\begin{tabular}{lllllllll}
\hline Paralog pairs & S-sites & N-sites & Ka & Ks & Ka/Ks & Selection pressure & Duplication type & Duplication time (Mya) \\
\hline CaANT1-CaANT2 & 304.25 & 970.75 & 0.16 & 0.57 & 0.29 & Purifying selection & Tandem & 40.96 \\
CaANT2-CaANT3 & 305.00 & 976.00 & 0.05 & 0.12 & 0.40 & Purifying selection & Tandem & 8.53 \\
CaANT1-CaANT3 & 304.83 & 970.17 & 0.15 & 0.57 & 0.26 & Purifying selection & Tandem & 40.59 \\
CaLHT1-CaLHT3 & 313.75 & 1015.25 & 0.13 & 0.58 & 0.22 & Purifying selection & Tandem & 41.43 \\
CaAAP1-CaAAP3 & 316.08 & 1015.92 & 0.07 & 0.14 & 0.50 & Purifying selection & Tandem & 10.37 \\
CaANT1-CaANT4 & 303.58 & 971.42 & 0.11 & 0.82 & 0.14 & Purifying selection & Segmental & 58.87 \\
CaAAP5-CaAAP6 & 351.08 & 1091.92 & 0.11 & 0.75 & 0.15 & Purifying selection & Segmental & 54.00
\end{tabular}

S-Sites number of synonymous sites, $N$-Sites number of non-synonymous sites, Ka non-synonymous substitution rate, Ks synonymous substitution, Mya million years ago

CaANT3, CaLHT1 and CaLHT3, and CaAAP1 and CaAAP3) were the result of a putative tandem duplication event. We further estimated nonsynonymous (Ka) and synonymous (Ks) nucleotide substitution rates in the coding sequences of paralog pairs to explore the selective pressures and duplication time of AAAP gene family members in pepper (Table 3 ). In general, $\mathrm{Ka} / \mathrm{Ks}$ ratios less than 1 indicate purifying selection, and $\mathrm{Ka} / \mathrm{Ks}$ ratios greater than 1 indicate positive selection [43]. The $\mathrm{Ka} / \mathrm{Ks}$ ratios of all seven paralog pairs were $<1.0$, which indicates that $C a A A A P$ genes evolved under purifying selection (Table 3). We also estimated the dates of duplication events of paralog pairs using the formula $\mathrm{T}=\mathrm{Ks} /$ $2 \lambda$ (assuming a clock-like rate $(\lambda)$ of $6.96 \times 10^{-9}$ synonymous substitutions per years [44]); duplication events were estimated to have occurred 8.53 to 68.69 million years ago (Mya), with an average duplication time of 43.61 Mya. We estimate that the duplication time of two AAAP paralog pairs in pepper occurred 58.87 to 54 Mya and that of five of the paralogous gene pairs occurred 40.96 to 8.53 Mya (Table 3).

\section{Expression patterns of CaAAAP genes in various tissues}

We investigated the expression profiles of all CaAAAP genes in roots, stems, leaves, floral buds, flowers and different developmental stages of fruits (Fig. 4, Additional file 4: Table S2). 48 (90.5\%) of the CaAAAP genes were detected in at least one tissue (RPKM $\geq 1$ ), and 19(35.8\%) genes were detected in all tissues tested (RPKM 21$)$. In particular, approximately half of the CaAAAP genes showed low expression in fruits. By contrast, approximately $50 \%$ CaAAAP genes showed high expression in flowers and buds (RPKM $\geq 10$ ). The CaAAAP genes clustered into three distinct clades based on expression patterns (Fig. 4). Seven genes (CaAAP2, CaAAP3, CaAAP5, CaAAP9, CaATL6, CaATL7, and CaVAAT8) in group I were expressed at relatively high levels in all tissues. In addition to several genes exhibited relatively high expression in specific organs (such as CaLHT3, CaLHT5, CaLHT8, VAAT1 and VAAT6 in buds; CaATL4 in fruits; CaLHT9 and CaGAT2 in roots;

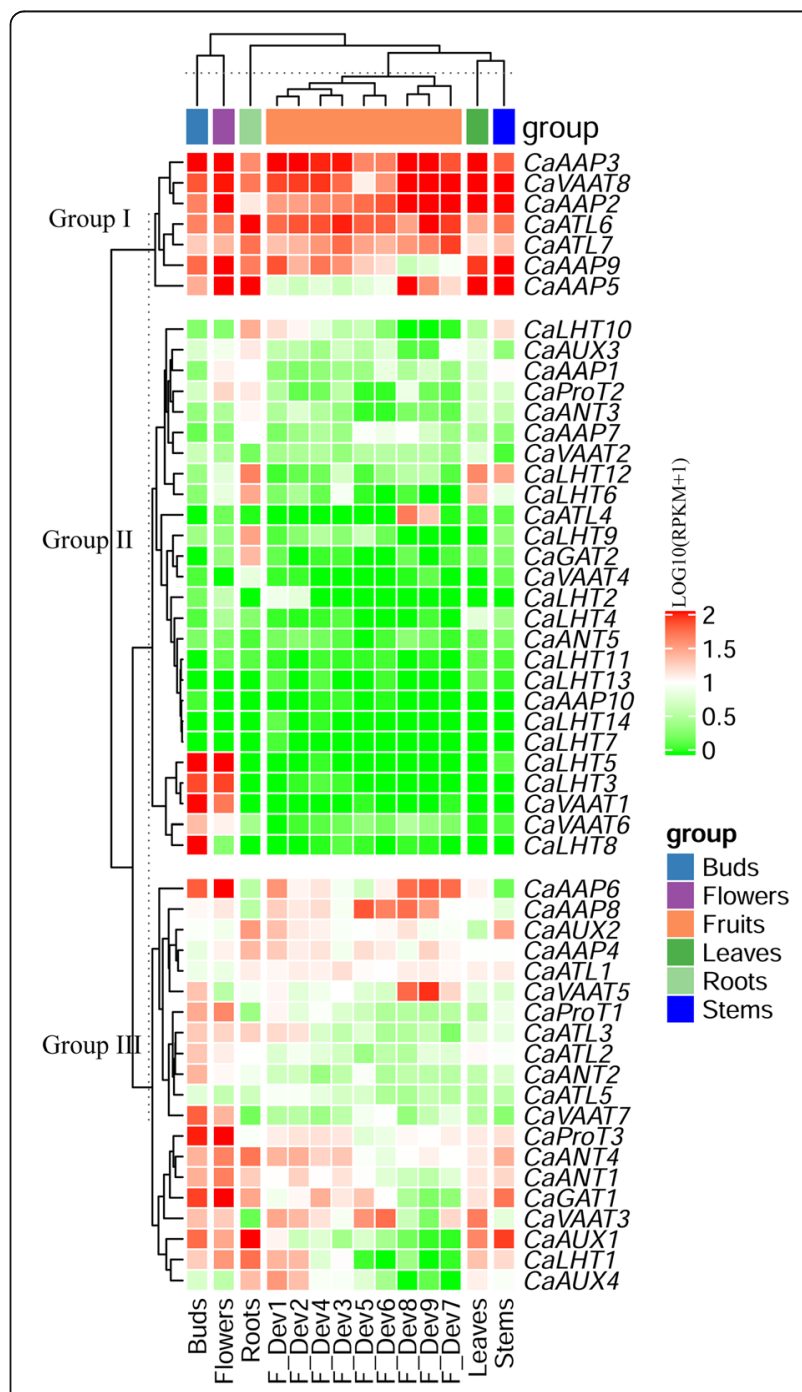

Fig. 4 Expression profiles of CaAAAP genes in different tissues. The relative expression levels corresponding to log 10-transformed RPKM values after the addition of a pseudocount of 1 are shown. The scale represents the relative signal intensity of the RPKM values 
CaLHT12 in roots, stems and leaves), the other genes in group II were expressed at relatively low levels in all tested tissues. Group III comprised 20 genes that were expressed at relatively high levels in most organs.

\section{Differential expression profiling of CaAAAP genes in response to hormones and abiotic stress}

To study whether CaAAAPs are involved in responses to hormones and abiotic stresses in pepper, we investigated the expression levels of the CaAAPs in the roots and leaves of 40-day old seedlings in response to cold, heat, salt, osmotic, oxidative, ABA, IAA, GA3, JA and SA treatment (Fig. 5, Additional file 5: Table S3). In addition to CaLHT2, CaLHT5, CaLHT7, CaLHT8, CaLHT13, and $C a A A P 10$, most $A A A P$ genes were induced in at least one of the treatment as compared with the control (Fig. 5). Interestingly, some $A A A P$ genes varied greatly between the leaves and roots in the response to abiotic or hormones stress. For instance, CaAAP4, CaLHT9, CaLHT10, CaATL3, CaATL6, CaATL7, CaAUX3, and CaVAAT7 were found to be upregulated under cold, heat, osomotic, oxidative and salt in the roots, but downregulated in the leaves. There were $28,10,20$, and $18 \mathrm{CaAAAP}$ genes were also upregulated by ABA, GA3, IAA, and JA treatment in the roots respectively, but downregulated in the leaves. Whereas there were 4, 5, and $7 \mathrm{CaAAAP}$ genes were observed to be upregulated in the leaves but downregulated in the roots under the cold, IAA and salt stress treatment, respectively. In contrast, the highest number of $C a A A A P$ genes were upregulated in the SA response in the leaves and roots (33 genes). There were several stress-responsive ciselements showing in the promoter regions of these members, such as ABRE, ARE, LTR, MBS, TGACGmotif, CGTCA-motif, TCA-element, GARE-motif, AuxRR-core, and TC-rich repeats (Additional file 6: Table S4). Among the 53 AAAP genes, the CaAAP7 promoter had no these stress-responsive elements, while CaVAAT2 had maximum 14 elements. These results reaveled that a number of $C A A A A P$ genes might involved in regulating abiotic and hormone stress responses.

\section{Discussion}

The AAAP gene family, which contains eight subfamilies, encodes integral TM proteins that play a pivotal role in various aspects of normal plant growth and development. This gene family has been identified in many plants, including Arabidopsis [6], rice [7], maize [8], poplar [9], potato [10], moso bamboo [11] and Medicago truncatula [12]. Although the role of AAAP genes in plants has been previously suggested, systematic study of the AAAP gene family in pepper has not been performed. We identified 53 CaAAAPs genes in C.annuum.Zunla-1 in this work. The number of CaAAAPs identified was similar to those in potato [10] and moso bamboo [11]. In addition, AAAP proteins account for 0.13 to $0.18 \%$ of the total proteins in many plant species studied (Table 2), and the percentage of CaAAAPs identified in the present study was $0.15 \%$.

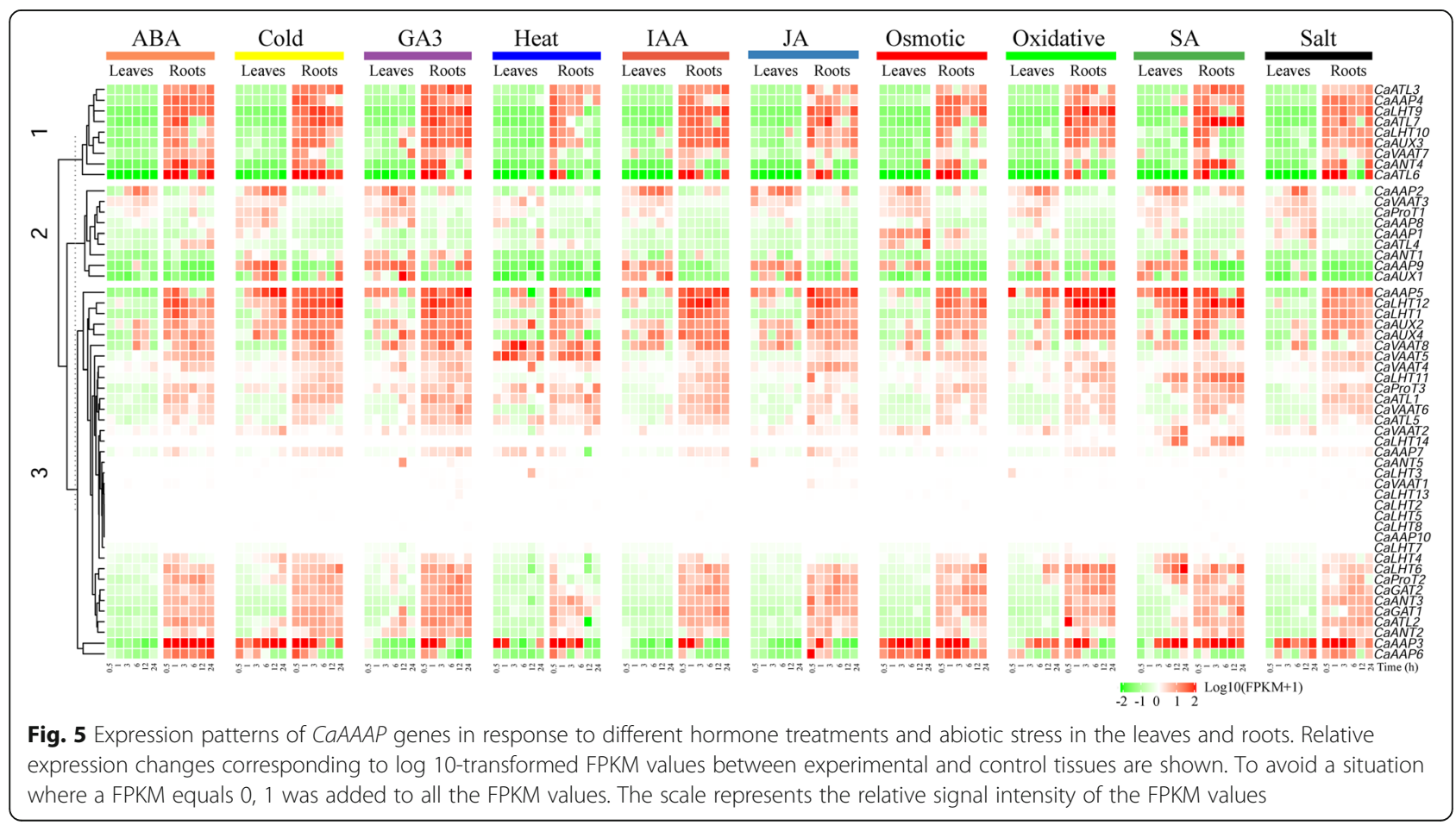


Thus, the number of AAAP genes in most plants appears to be similar, regardless of genome size. Consistent with that in other plants, the pepper AAAP gene family can be divided into eight subfamilies (Fig. 2 and Table 2). Although the clade patterns are consistent with previous results from in other plants, the number of AAAP genes within sevearl subfamilies is significant difference (Table 2), which indicates that the expansion of each subfamily occurred after the split of dicot and monocot.

In addition to CaGAT1, CaVATT1 and CaATL4, the remaining 50 genes were unevenly distributed on 11 of 12 chromosomes, and most of the genes were mapped on chromosomes 2, 3, 4 and 5 (Fig. 3). Meanwhile, four groups of tandem duplicate genes were identified on chromosome 2, 5 and 7, respectively, and segmental duplication blocks were located on chromosomes 2, 4 and 12 respectively (Fig. 3). In addition, gene structure analysis indicated the same subgroup had the same or similar numbers and types of exon/intron, TM regions, and motif compositions (Fig. 1, Table 1), which suggests that those groups have been relatively conserved during evolution.

Gene duplication is generally considered a major source of gene family expansion and functional diversity during evolution [45]. Previous studies also showed that $50 \%(29 / 58)$ of $A A A P$ genes are duplicated gene in rice [7], duplicated genes represented $32.69 \%(17 / 52)$ in potato [10] and $30.43 \%(14 / 46)$ in Arabidopsis [6]. In the present study, $33.96 \%$ of $A A A P$ genes (18/53) in pepper were duplicated genes, 12 genes (22.64\%) are involved in the tandem duplication, and 6 genes (11.32\%) in segmental duplication. These results suggest that tandem gene duplication is the main cause of expansion of the CaAAAP gene family; similar results have been reported in potato and Arabidopsis $[6,10]$. The two pairs (CaANT1 and CaANT4, and CaAAP5 and CaAAP6) of paralogs participated in segmental duplications occurred from 54 to 58.87 Mya, and five pairs (CaANT1 and CaANT2, CaANT2 and CaANT3, CaANT1 and CaANT3, CaLHT1 and CaLHT3, and CaAAP1 and CaAAP3) participated in tandem duplications occurred from 41.43 to 8.53 Mya (Table 3). This indicated that the segmental duplication of AAAPs in pepper occurred before tandem duplication. The pepper/potato separation occurred approximately 36 Mya [46], the duplication of most AAAP paralog pairs occurred before their separation from pepper and potato, and only two paralogous pairs were duplicated after the pepper/potato split. The $\mathrm{Ka} / \mathrm{Ks}$ ratios of seven paralog pairs were $<1$ (Table 3), which indicates that these paralog pairs evolved under purifying selection. Similar results have been reported in moso bamboo [11] and poplar [9], which have no paralog pairs in the AAAP family that underwent positive selection.
Gene duplication often causes changes in gene expression patterns and original functions of these genes may be retained [45]. Comparative analysis of the expression pattern of duplicated CaAAAP genes revealed that CaANT2 and CaANT3 (tandem duplicated genes) exhibited similar expression patterns in various development stages and stresses, which indicated that they may have overlapping functions (Figs. 4 and 5). However, most duplicated $C a A A A P$ genes exhibited distinct expression patterns, such as CaAAP5 and CaAAP6 (segmental duplicated genes); as well as CaAAP1 and CaAAP3, CaLHT1 and CaLHT3 (tandem duplicated genes) (Figs. 4 and 5). These results indicate that the expression and functional divergence of duplicated genes under selection pressure, contributing to adapt to the diversity of the environment.

Gene expression patterns are usually closely linked to plant growth and development, and comparative expression analyses of gene families can provide useful information for establishing their putative functions [47]. In this study, the expression profiles of CaAAAP differed across different organs and stages, consistent with the results of studies in other species such as potato [10]. Approximately 50\% CaAAAP genes were expressed at relatively high levels in flowers and buds. 24 and 19 CaAAAPs genes showed relatively high expression levels in the roots and leaves, respectively. Similarly, 19 StAATs in potato were expressed at relatively high levels in the leaves [10]. Our data showed that $C a A A P 5$, an orthologous of StAAP1 and AtAAP6, was highly expressed in flowers, roots, leaves, and stems (Fig. 4). AtAAP6 is responsible for the long-distance transport of amino acids [20]. StAAP1, which is highly expressed in leaves, stem, stolon and young tuber, is also responsible for the long-distance transport of amino acids [25]. Therefore, CaAAP5 might be involved in the longdistance transport of amino acid in pepper. In Arabidopsis, AtAUX1 and AtLAX3 are highly expressed in roots $[37,48]$. AUX subfamily genes are also mainly expressed in roots of rice and potato $[7,10]$. In the study, AUX subfamily genes exhibited relatively high expression in roots, which indicates that CaAUXs might be involved in root growth and development. CaATL4 was only expressed at a high level in F-Dev-8 and F-Dev-9, suggesting that CaATL4 could play important roles in the late fruit developmen. Taken together, these results indicate that $C a A A A P$ s may play an important role in the growth and development of pepper.

It has been reported that AAAPs is regulated by low temperature, high salt, and/or drought stress treatments in many plants [40, 49]. Under abiotic stress, 47 genes were regulated in at least one of the treatment as compared with the control and the expression of 48 genes were observed in all tissue analysis (Figs. 4 and 5). It has 
been reported that HvProT and AtProT2 were strongly induced by salt stress $[49,50]$. Similarly, we found that CaProT1 had a close relationship with AtProT2, was specifically upregulated by cold, heat, salt, osmotic, oxidative, IAA, GA3, JA and SA stress in leaves. On the contrary, AtAAP6 were found to be downregulated by salt stress [50]. CaAAP5, which is orthologous to AtAAP6, was downregulated under salt stress in leaves, but upregualtaed in roots. In moso bamboo, the AAP subfamily gene PeAAAP9 has low expression level in leaf, but it is strongly induced by drought, cold and salt stress treatment [11]. Similary, CaAAP6 was highly expressed under all ten stresses treatment in the roots. However, low expression of this gene was observed in root, suggesting that CaAAP6 may take part in abiotic stress signaling pathways. With respect to the ten treatments, the expression of most CaAAAP was induced in the leaves or roots, suggesting that CaAAAP may play different roles in stress responses in pepper.

\section{Conclusions}

Overall, 53 AAAP gene family members were identified in the 'Zunla-1' pepper genome and could be divided into eight subgroups. Throughout its evolutionary history, CaAAAPs were highly conserved and expanded slowly. CaAAAP genes exhibit tissue-specific expression and coordinate to regulate growth and development in pepper.

\section{Methods}

\section{Data retrieval and identification of gene families}

All pepper protein sequences were obtained from the Pepper Genome Database2 (http://peppersequence.genomics. $\mathrm{cn} /$ page/). The HMM profile for the AAAP domain (PF01490) downloaded from the Pfam database (http:// pfam.xfam.org) [51], was used to identify potential AAAP genes from the pepper genome with HMMER 3.2.1 (http:// hmmer.janelia.org/), with an E-value of $10^{-2}$ [47]. BLAST analyses using the rice and Arabidopsis AAAPs as queries against the pepper genome with an E-value threshold of $10^{-10}$. The sequences of the rice and Arabidopsis AAAP family were obtained from JGI (https://phytozome.jgi.doe. gov/pz/portal.html). After merging all of the putative pepper AAAP sequences, the candidate protein sequences were further verified for the presence of conserved domains with the online tools Conserved Domain Database (http://www. ncbi.nlm.nih.gov/cdd/), SMART (http://smart.emblheidelberg.de/), and pfam (http://pfam.xfam.org/). The results were integrated and redundant genes were discarded. Molecular weights and pIs of the proteins encoded by the identified genes were predicted with the online EXPASY serve (http://web.expasy.org/protparam/).
Phylogenetic tree, gene structure and conserved motif analyses of CaAAAP genes

Multiple sequence alignments analyses of AAAP amino acid sequences of Arabidopsis, rice, potato and pepper were performed with ClustalW. We built the phylogenetic tree using the neighbor-joining method with MEGA7 [52] and 1000 bootstrap replications, a Poisson model, and partial deletion gap parameters. We determined the exon/intron organization of CaAAAP genes by aligning the coding sequences with genomic sequences using the Gene Structure Display Server (http:// gsds.cbi.pku.edu.cn/) [53]. Conserved motifs were generated with MEME (http://meme-suite.org/tools/meme) with the following parameters: zero or one motif in each sequence, 10 and 100 width of motifs, and a maximum of 20 motifs. Motifs were visualized with TBtools [54].

\section{Chromosomal location and syntenic analyses}

The physical positions of the CaAAAP genes were obtained from the pepper annotation file deposited in the Sol Genomics database, mapped to 12 chromosomes, and visualized with Mapchart v.2.32 [55]. For syntenic analyses of CaAAAP genes, we used MCScanX [56] with the default settings to identify gene pairs of segmental and tandem duplications within the pepper genome.

\section{Expression patterns of $C a A A A P$ genes in various tissues and different stresses}

To study the expression patterns of pepper $A A A P$ genes in the pepper plant, we downloaded transcriptome sequencing data from the NCBI (https://www.ncbi.nlm. nih.gov/geo/; accession no.GSE45037) [46]. These data covered a wide range of developmental stages of pepper: roots, stems and leaves from plants at the full-bloom stage; unopened flower buds (buds) and fully open flowers (flowers) from mature plants; and fruits lengths of $0-1,1-3,3-4$, and 4-5 cm (F-Dev-1, F-Dev-1, F-Dev-3 and F-Dev-4, respectively); mature green fruit (F-Dev-5); fruit turning red (F-Dev-6); and fruit 3, 5, and 7 days after turning red (F-Dev-7, F-Dev-8, and F-Dev-9, respectively). A heat map representing digital expression profile of CaAAAP genes was created with $\mathrm{R} 3.6 .3$ with logtransformed values.

The gene expression data of pepper in roots and leaves under different stresses were downloaded from (http:// pepperhub.hzau.edu.cn/) [57]. The 40-day-old seedlings were separately treated with 10 stress conditions in 0 , $0.5,1,3,6,12$ and $24 \mathrm{~h}$ : cold stress $\left(10^{\circ} \mathrm{C}\right)$, heat stress $\left(42^{\circ} \mathrm{C}\right)$, salt stress $(200 \mathrm{mM} \mathrm{NaCl})$, osmotic stress $(400$ $\mathrm{mM}$ D-mannitose), oxidative stress (30 $\left.\mathrm{mM} \mathrm{H}_{2} \mathrm{O}_{2}\right), \mathrm{ABA}$ stress $(30 \mu \mathrm{M})$, IAA stress $(2 \mu \mathrm{M})$, GA3 $(2 \mu \mathrm{M})$, JA $(10 \mu \mathrm{M})$ and SA $(2 \mathrm{mM})$. A heat map representing digital expression profile of $C a A A A P$ genes was created with $\mathrm{R}$ 3.6.3 with log-transformed values. 


\section{Abbreviations}

RPKM: Reads Per Kilo bases per Million reads; FPKM: Fragments Per Kilo bases per Million reads

\section{Supplementary Information}

The online version contains supplementary material available at https://doi. org/10.1186/s12864-021-07765-1.

Additional file 1: Figure S1. Prediction of the transmembrane regions of 53 CaAAAPs. The transmembrane regions of the 53 CaAAAPs were predicted using the TMHMM Server v2.0 (http://www.cbs.dtu. dkservicesTMHMM).

Additional file 2: Figure S2. Segmental duplication of 53 CaAAAPs. Gray lines indicate all synteny blocks in the pepper genome, the red lines indicate segmental duplicated genes.

Additional file 3: Table S1. MEME motif sequences and lengths of AAAP gene family proteins in pepper.

Additional file 4: Table S2. The RPKM expression values of CaAAAP genes at various developmental stages. These primary data was downloaded from NCBI, and then the relative expression level (log10 expression values) of 14 different tissues or evelopment stages was obtained after a series of manual processing.

Additional file 5: Table S3. Sample list and the FPKM data of CaAAAP genes under various stress treatment.

Additional file 6: Table S4. Summary of abiotic-stress inducible ciselements in the promoter regions of AAAP genes in pepper.

\section{Acknowledgements}

Not Applicable.

\section{Authors' contributions}

The study was conceived and designed by $\mathrm{KL}$ and $\mathrm{XP}, \mathrm{MH}$, ZW, and HW contributed to data collection and bioinformatics analysis. $\mathrm{KL}$ and $\mathrm{XP}$ participated in preparing and writing the manuscript. All authors contributed to revising the manuscript. The author(s) read and approved the final manuscript.

\section{Funding}

The research was financially supported by the Chongqing Technology Innovation and Application Development Project (cstc2020jscx-msxmX0054).

\section{Availability of data and materials}

All the data obtained in the current study have been presented in this article.

\section{Declarations}

\section{Ethics approval and consent to participate}

Not applicable.

\section{Consent for publication}

Not applicable.

\section{Competing interests}

The authors declare that they have no competing interests.

Received: 7 September 2020 Accepted: 3 June 2021 Published online: 22 June 2021

\section{References}

1. Williams LE, Miller AJ. Transporters responsible for the uptake and partitioning of nitrogenous solutes. Annu Rev Plant Physiol Plant Mol Biol. 2001;52(1):659-88. https://doi.org/10.1146/annurev.arplant.52.1.659.

2. Tegeder M. Transporters for amino acids in plant cells: some functions and many unknowns. Curr Opin Plant Biol. 2012;15(3):315-21. https://doi.org/1 0.1016/j.pbi.2012.02.001.
3. Saier MH Jr, Reddy VS, Tsu BV, Ahmed MS, Li C, Moreno-Hagelsieb G. The transporter classification database (TCDB): recent advances. Nucleic Acids Res. 2016;44(D1):D372-9. https://doi.org/10.1093/nar/gkv1103.

4. Okumoto S, Pilot G. Amino acid export in plants: a missing link in nitrogen cycling. Mol Plant. 2011;4(3):453-63. https://doi.org/10.1093/mp/ssr003.

5. Fischer WN, André B, Rentsch D, Krolkiewicz S, Tegeder M, Breitkreuz K, et al. Amino acid transport in plants. Trends Plantence. 1998;3(5):188-95. https:// doi.org/10.1016/S1360-1385(98)01231-X.

6. Rentsch D, Schmidt S, Tegeder M. Transporters for uptake and allocation of organic nitrogen compounds in plants. FEBS Lett. 2007;581(12):2281-9. https://doi.org/10.1016/j.febslet.2007.04.013.

7. Zhao H, Ma H, Yu L, Wang X, Zhao J. Genome-wide survey and expression analysis of amino acid transporter gene family in rice (Oryza sativa L.). Plos One. 2012;7(11):e49210.

8. Sheng L, Deng L, Yan HW, Zhao Y, Dong Q, Li Q, Li XY, Cheng BJ, Jiang HY. A genome-wide analysis of the AAAP gene family in maize. J Proteomics Bioinformatics. 2014; 07(1).

9. Wu M, Wu SN, Chen Z, Dong Q, Yan HW, Xiang Y. Genome-wide survey and expression analysis of the amino acid transporter gene family in poplar. Tree Genet Genomes. 2015;11(4):83. https://doi.org/10.1007/s11295-0150908-4.

10. Ma HL, Cao XL, Shi SD, Li SL, Gao JP, Ma YL, et al. Genome-wide survey and expression analysis of the amino acid transporter superfamily in potato (Solanum tuberosum L.). Plant Physiol Biochem. 2016;107:164-77. https:// doi.org/10.1016/.jplaphy.2016.06.007.

11. Liu HL, Wu M, Zhu DY, Pan F, Wang Y, Wang YJ, et al. Genome-wide analysis of the AAAP gene family in moso bamboo (Phyllostachys edulis). BMC Plant Biol. 2017;17(1):29. https://doi.org/10.1186/s12870017-0980-z.

12. Qu Y, Ling L, Wang D, Zhang T, Guo CH. Genome-wide identification and expression analysis of the AAAP family in Medicago truncatula. Genetica. 2019;147(2):185-96. https://doi.org/10.1007/s10709-019-00062-6.

13. Fischer WN, Kwart M, Hummel S, Frommer WB. Substrate specificity and expression profile of amino acid transporters (AAPs) in Arabidopsis. J Biol Chem. 1995;270(27):16315-20. https://doi.org/10.1074/jbc.270.27.16315.

14. Okumoto S, Schmidt R, Tegeder M, Fischer WN, Rentsch D, Frommer WB, et al. High affinity amino acid transporters specifically expressed in xylem parenchyma and developing seeds of Arabidopsis. J Biol Chem. 2002; 277(47):45338-46. https://doi.org/10.1074/jbc.M207730200.

15. Hirner B, Fischer WN, Rentsch D, Kwart M, Frommer WB. Developmental control of $\mathrm{H}+$ /amino acid permease gene expression during seed development of Arabidopsis. Plant J. 1998;14(5):535-44. https://doi.org/10.1 046/j.1365-313X.1998.00151.X.

16. Lee YH, Foster J, Chen J, Voll LM, Weber AP, Tegeder M. AAP1 transports uncharged amino acids into roots of Arabidopsis. Plant J. 2007;50(2):305-19. https://doi.org/10.1111/j.1365-313X.2007.03045.X

17. Sanders A, Collier R, Trethewy A, Gould G, Sieker R, Tegeder M. AAP1 regulates import of amino acids into developing Arabidopsis embryos. Plant J. 2009;59(4):540-52. https://doi.org/10.1111/j.1365-313X.2009.03890.x.

18. Zhang LZ, Tan QM, Lee R, Trethewy A, Lee YH, Tegeder M. Altered xylemphloem transfer of amino acids affects metabolism and leads to increased seed yield and oil content in Arabidopsis. Plant Cell. 2010;22(11):3603-20. https://doi.org/10.1105/tpc.110.073833.

19. Okumoto S, Koch W, Tegeder M, Fischer WN, Biehl A, Leister D, et al. Root phloem-specific expression of the plasma membrane amino acid proton co-transporter AAP3. J Exp Bot. 2004;55(406):2155-68. https://doi.org/10.1 093/jxb/erh233.

20. Hunt E, Gattolin S, Newbury HJ, Bale JS, Tseng HM, Barrett DA, et al. A mutation in amino acid permease AAP6 reduces the amino acid content of the Arabidopsis sieve elements but leaves aphid herbivores unaffected. J Exp Bot. 2010;61(1):55-64. https://doi.org/10.1093/jxb/erp274.

21. Schmidt $R$, Stransky $H$, Koch $W$. The amino acid permease AAP8 is important for early seed development in Arabidopsis thaliana. Planta. 2007; 226(4):805-13. https://doi.org/10.1007/s00425-007-0527-x.

22. Lu K, Wu B, Wang J, Zhu W, Nie HP, Qian JJ, et al. Blocking amino acid transporter OsAAP3 improves grain yield by promoting outgrowth buds and increasing tiller number in rice. Plant Biotechnol J. 2018;16(10):1710-22. https://doi.org/10.1111/pbi.12907.

23. Wang J, Wu B, Lu K, Wei Q, Qian JJ, Chen YP, et al. The amino acid permease 5 (OsAAP5) regulates tiller number and grain yield in rice. Plant Physiol. 2019;180(2):1031-45. https://doi.org/10.1104/pp.19.00034. 
24. Peng B, Kong $H$, Li Y, Wang $L$, Zhong $M$, Sun $L$, et al. OsAAP6 functions as an important regulator of grain protein content and nutritional quality in rice. Nat Commun. 2014;5(1):4847. https://doi.org/10.1038/ncomms5847.

25. Koch W, Kwart M, Laubner M, Heineke D, Stransky H, Frommer WB, et al. Reduced amino acid content in transgenic potato tubers due to antisense inhibition of the leaf H+/amino acid symporter StAAP1. Plant J. 2003;33(2): 211-20. https://doi.org/10.1046/j.1365-313X.2003.01618.x.

26. Tan Q, Grennan AK, Hélène C, Pélissier RD, Tegeder M. Characterization and expression of French bean amino acid transporter PvAAP1. Plant Sci. 2008; 174(3):348-56. https://doi.org/10.1016/j.plantsci.2007.12.008.

27. Couturier J, de Faÿ E, Fitz M, Wipf D, Blaudez D, Chalot M. PtAAP11, a high affinity amino acid transporter specifically expressed in differentiating xylem cells of poplar. J Exp Bot. 2010;61(6):1671-82. https://doi.org/10.1093/jxb/ erq036.

28. Miranda M, Borisjuk L, Tewes A, Heim U, Sauer N, Wobus U, et al. Amino acid permeases in developing seeds of Vicia faba $L$.: expression precedes storage protein synthesis and is regulated by amino acid supply. Plant $\mathrm{J}$. 2001;28(1):61-71. https://doi.org/10.1046/j.1365-313X.2001.01129.X.

29. Chen L, Bush DR. LHT1, a lysine- and histidine-specific amino acid transporter in arabidopsis. Plant Physiol. 1997;115(3):1127-34. https://doi org/10.1104/pp.115.3.1127

30. Hirner A, Ladwig F, Stransky H, Okumoto S, Keinath M, Harms A, et al. Affiliations expand Arabidopsis LHT1 is a high-affinity transporter for cellular amino acid uptake in both root epidermis and leaf mesophyll. Plant Cell. 2006;18(8):1931-46. https://doi.org/10.1105/tpc.106.041012.

31. Lee $\mathrm{YH}$, Tegeder M. Selective expression of a novel high-affinity transport system for acidic and neutral amino acids in the tapetum cells of Arabidopsis flowers. Plant J. 2004;40(1):60-74. https://doi.org/10.1111/j.13 65-313X.2004.02186.x.

32. Perchlik M, Foster J, Tegeder M. Different and overlapping functions of Arabidopsis LHT6 and AAP1 transporters in root amino acid uptake. J Exp Bot. 2014;65(18):5193-204. https://doi.org/10.1093/jxb/eru278.

33. Foster J, Lee YH, Tegeder M. Distinct expression of members of the LHT amino acid transporter family in flowers indicates specific roles in plant reproduction. Sex Plant Reprod. 2008;21(2):143-52. https://doi.org/10.1007/ s00497-008-0074-z

34. Zhang R, Zhu J, Cao HZ, Xie XL, Hung JJ, Chen XH, et al. Isolation and characterization of LHT-type plant amino acid transporter gene from Panax ginseng Meyer. J Ginseng Res. 2013;37(3):361-70. https://doi.org/10.5142/ jgr.2013.37.361.

35. Meyer A, Eskandari S, Grallath S, Rentsch D. AtGAT1, a high affinity transporter for gamma-aminobutyric acid in Arabidopsis thaliana. $J$ Biol Chem. 2006;281(11):7197-204. https://doi.org/10.1074/jbc.M51 0766200 .

36. Chen L, Ortiz-Lopez A, Jung A, Bush DR. ANT1, an aromatic and neutral amino acid transporter in Arabidopsis. Plant Physiol. 2001;125(4):1813-20. https://doi.org/10.1104/pp.125.4.1813.

37. Ugartechea-Chirino Y, Swarup R, Swarup K, Péret B, Whitworth M, Bennett $M$. The AUX ${ }_{1}$ LAX family of auxin influx carriers is required for the establishment of embryonic root cell organization in Arabidopsis thaliana. Ann Bot. 2010;105(2):277-89. https://doi.org/10.1093/aob/mcp287.

38. Marchant A, Kargul J, May ST, Muller P, Delbarre A, Perrot-Rechenmann C, et al. AUX1 regulates root gravitropism in Arabidopsis by facilitating auxin uptake within root apical tissues. EMBO J. 1999;18(8):2066-73. https://doi. org/10.1093/emboj/18.8.2066

39. Roy S, Robson F, Lilley J, Liu CW, Cheng X, Wen J, et al. MtLAX2, a functional homologue of the Arabidopsis auxin influx transporter AUX1, is required for nodule organogenesis. Plant Physiol. 2017;174(1):326-38. https://doi.org/10.1104/pp.16.01473.

40. Grallath S, Weimar T, Meyer A, Gumy C, Suter-Grotemeyer M, Neuhaus JM, et al. The AtProT family. Compatible solute transporters with similar substrate specificity but differential expression patterns. Plant Physiol. 2005; 137(1):117-26. https://doi.org/10.1104/pp.104.055079.

41. Fujiwara T, Mitsuya S, Miyake H, Hattori T, Takabe T. Characterization of a novel glycinebetaine/proline transporter gene expressed in the mestome sheath and lateral root cap cells in barley. Planta. 2010;232(1):133-43. https://doi.org/10.1007/s00425-010-1155-4.

42. Fujiki $Y$, Teshima H, Kashiwao S, Kawano-Kawada M, Ohsumi $Y$, Kakinuma $Y$, et al. Functional identification of AtAVT3, a family of vacuolar amino acid transporters, in Arabidopsis. FEBS Lett. 2017;591(1):5-15. https://doi.org/10.1 002/1873-3468.12507.
43. Koonin EV, Rogozin IB. Getting positive about selection. Genome Biol. 2003; 4(8):331. https://doi.org/10.1186/gb-2003-4-8-331.

44. Moniz de Sá M, Drouin G. Phylogeny and substitution rates of angiosperm actin genes. Mol Biol Evol. 1996;13(9):1198-212. https://doi.org/10.1093/ oxfordjournals.molbev.a025685.

45. Kong H, Landherr LL, Frohlich MW, Leebens-Mack J, Ma H, dePamphilis CW. Patterns of gene duplication in the plant SKP1 gene family in angiosperms: evidence for multiple mechanisms of rapid gene birth. Plant J 2007;50(5): 873-885, doi: https://doi.org/10.1111/j.1365-313X.2007.03097.x.

46. Qin C, Yu C, Shen Y, Fang X, Chen L, Min J, et al. Whole-genome sequencing of cultivated and wild peppers provides insights into Capsicum domestication and specialization. Proc Natl Acad Sci U S A. 2014;111(14): 5135-40. https://doi.org/10.1073/pnas.1400975111.

47. Liu AK, Liu CL, Lei HY, Wang ZJ, Zhang M, Yang XR, et al. Phylogenetic analysis and transcriptional profiling of WRKY genes in sunflower (Helianthus annuus L.): genetic diversity and their responses to different biotic and abiotic stresses. Ind Crops Products. 2020;148(6):112268.

48. Yang Y, Hammes UZ, Taylor CG, Schachtman DP, Nielsen E. High-affinity auxin transport by the AUX1 influx carrier protein [published correction appears in Curr biol. Curr Biol 2006;16(11):1123-1127, doi: https://doi.org/1 0.1016/j.cub.2006.04.029

49. Ueda A, Shi W, Sanmiya K, Shono M, Takabe T. Functional analysis of saltinducible proline transporter of barley roots. Plant Cell Physiol. 2001;42(11): 1282-9. https://doi.org/10.1093/pcp/pce166.

50. Rentsch D, Hirner B, Schmelzer E, Frommer WB. Salt stress-induced proline transporters and salt stress-repressed broad specificity amino acid permeases identified by suppression of a yeast amino acid permeasetargeting mutant. Plant Cell. 1996;8(8):1437-46. https://doi.org/10.1105/tpc.8. 8.1437 .

51. El-Gebali S, Mistry J, Bateman A, et al. The Pfam protein families database in 2019. Nucleic Acids Res. 2019;47(D1):D427-32. https://doi.org/10.1093/nar/ gky995.

52. Kumar S, Stecher G, Tamura K. MEGA7: molecular evolutionary genetics analysis version 7.0 for bigger datasets. Mol Biol Evol. 2016;33(7):1870-4. https://doi.org/10.1093/molbev/msw054.

53. Hu B, Jin J, Guo AY, Zhang H, Luo J, Gao G. GSDS 2.0: an upgraded gene feature visualization server. Bioinformatics. 2015;31(8):1296-7. https://doi. org/10.1093/bioinformatics/btu817.

54. Chen CJ, Chen H, Zhang Y, Thomas HR, Frank MH, He YH, et al. TBtools: an integrative toolkit developed for interactive analyses of big biological data. Mol Plant. 2020;13(8):1194-202. https://doi.org/10.1016/j.molp.2020.06.009.

55. Voorrips RE. MapChart: software for the graphical presentation of linkage maps and QTLs. J Hered. 2002;93(1):77-8. https://doi.org/10.1093/jhered/ 93.1.77.

56. Wang $Y$, Tang H, Debarry JD, et al. MCScanX: a toolkit for detection and evolutionary analysis of gene synteny and collinearity. Nucleic Acids Res. 2012;40(7):e49. https://doi.org/10.1093/nar/gkr1293.

57. Liu F, Yu H, Deng Y, Zheng J, Liu M, Ou L, et al. PepperHub, an informatics hub for the chili pepper research community. Mol Plant. 2017;10(8):1129-32. https://doi.org/10.1016/j.molp.2017.03.005

\section{Publisher's Note}

Springer Nature remains neutral with regard to jurisdictional claims in published maps and institutional affiliations.

Ready to submit your research? Choose BMC and benefit from:

- fast, convenient online submission

- thorough peer review by experienced researchers in your field

- rapid publication on acceptance

- support for research data, including large and complex data types

- gold Open Access which fosters wider collaboration and increased citations

- maximum visibility for your research: over $100 \mathrm{M}$ website views per year

At $\mathrm{BMC}$, research is always in progress.

Learn more biomedcentral.com/submissions 